Научная статья

УДК 3.304 .4

DOI: $10.17213 / 2075-2067-2021-6-246-256$

\title{
«ЗЕЛЕНАЯ» ЭКОНОМИКА КАК ФАКТОР УСТОЙЧИВОГО ЭКОЛОГИЧЕСКОГО РАЗВИТИЯ СОВРЕМЕННОГО ГОРОДА
}

\author{
Татьяна Николаевна Майснер
}

\section{Южсно-Российский государственный политехнический университет (НПИ) имени М. И. Платова, Новочеркасск, Россия designtatyana@yandex.ru,ORCID:0000-0001-8654-0881, AuthorID РИНЦ: 345191, SPIN-код: 2057-0869}

Аннотация. Цель статьи заключается в изучении экологических проблем современных городов, решение которых возможно на основе внедрения модели «зеленой» экономики.

Методология исследования представлена совокупностью следующих теоретических подходов: системный подход, позволяющий рассматривать город как сочиоэкосистему, устойчивое развитие которой зависит от всех ее элементов; синергетический подход, открывающий возможность для понимания сложного нелинейного характера взаимосвязи и взаимовлияния различных сфер общества; положения современных теорий урбанизации, позволяющие понять эволючию города, связанную с расширением городской территории и вытеснением природной средь;; теория «общества риска», которая позволяет учитывать и систематизировать риски развития современного города; идеи теоретиков «зеленой экономики» и др.

Результаты исследования. Автор обращает внимание на то, что «зеленую» экономику следует рассматривать как новую экономическую модель, которая должна прийти на смену нынешней рыночной модели, где доминируют принщиипь либеральной идеологии. Развитие «зеленой» экономики кардинально трансформирует инфраструктуру города и способствует появлению экологических городов - экосити. В статье анализируются причины, затрудняющие развитие экосити в России.

Перспективы использования результатов исследования. Результаты исследования могут быть использованы для дальнейшего анализа сочииально-экологических проблем современных городов, а также для развития современной экологической политики.

Ключевые слова: «зеленая» экономика, современный город, устойчивое развитие, «зеленые» технологии, экосити, экополис, экологическая инфраструктура, технополис

Для цитирования: Майснер Т.Н. «Зеленая» экономика как фактор устойчивого экологического развития современного города // Вестник Южно-Российского государственного технического университета. Серия: Социально-экономические науки. 2021. T. 14, № 6. C. 246-256. http://dx.doi.org/10.17213/2075-2067-2021-6-246-256.

(C) Майснер Т.Н., 2021 
Original article

\title{
GREEN ECONOMY AS A FACTOR OF SUSTAINABLE ENVIRONMENTAL DEVELOPMENT OF A MODERN CITY
}

\author{
Tatyana N. Meisner
}

\author{
Platov South Russian State Polytechnic University (NPI), Novocherkassk, Russia \\ designtatyana@yandex.ru, ORCID:0000-0001-8654-0881, \\ AuthorID RSCI: 345191, SPIN: 2057-0869
}

\begin{abstract}
The purpose of the article is to study the environmental problems of modern cities, the solution of which is possible on the basis of the implementation of the "green" economy model.

The research methodology is presented by a set of the following theoretical approaches: a systematic approach that allows us to consider the city as a socio-ecosystem, the sustainable development of which depends on all its elements; a synergetic approach that opens up the possibility for understanding the complex nonlinear nature of the relationship and mutual influence of various spheres of society; the provisions of modern theories of urbanization, allowing us to understand the evolution of the city associated with the expansion of the urban area and the displacement of the natural environment; the theory of the "risk society", which allows you to take into account and systematize the risks of the development of a modern city; the ideas of the theorists of the "green economy», etc.

The results of the study. The author draws attention to the fact that the "green" economy should be considered as a new economic model, which should replace the current market model, where the principles of liberal ideology dominate. The development of the "green» economy radically transforms the infrastructure of the city and contributes to the emergence of ecological cities - ecocity. The article analyzes the reasons that hinder the development of ecocity in Russia.

Prospects for using the results of the study. The results of the study can be used for further analysis of socio-ecological problems of modern cities, as well as for the development of modern environmental policy.
\end{abstract}

Keywords: «green» economy, modern city, sustainable development, "green» technologies, ecosity, ecopolis, ecological infrastructure, technopolis

For citation: Meisner T. N. Green economy as a factor of sustainable environmental development of a modern city // Bulletin of the South Russian State Technical University. Series: Socio-economic Sciences. 2021; 14(6): 246-256. (In Russ.). http://dx.doi.org/10.17213/2075-2067-2021-6-246-256.

Введение. В настоящее время большинство городов представляют собой, с одной стороны, центры активной экономической деятельности, являются сосредоточением научно-технологических достижений и местом культурной жизни людей, а с другой — являются зонами экологического неблагополучия (мусорные свалки, наличие городских трущоб и других источников санитарно-эпидемиологических угроз). Выступая драйвером развития цивилизации, города стали акторами деградации природ- ной среды и создали массу экологических проблем.

Основным источником деградации городской среды считается сфера экономики, функционирование которой осуществляется, во-первых, за счет природных ресурсов, во-вторых, сопровождается появлением промышленных отходов, влекущих за собой загрязнение природной среды. В этой связи необходимо рационализировать отношения между дальнейшим экономическим развитием и сохранением биосферы. 
Дальнейшее безопасное развитие цивилизации по вектору урбанизации возможно только при условии решения экологических проблем современного города. В этой связи актуализировался вопрос о дальнейшем развитии городского хозяйства и возможностях «экологической» реконструкции городов с целью сделать их безопасными для жизни людей и окружающей среды. Одним из направлений для снижения антропогенной нагрузки на биосистему выступает развитие «зеленой» экономики.

Материалы и методы. В статье были использованы различные методы исследования, в том числе системный подход, разработанный в трудах М. Вебера [1], Д. Харви ${ }^{1}$, позволяющий рассматривать город как социоэкосистему, устойчивое развитие которой зависит от всех ее элементов; синергетический подход, открывающий возможность для понимания сложного нелинейного характера взаимосвязи и взаимовлияния различных сфер общества социально-экономической, технологической, духовной, экологической [2].

В статье используются положения современных теорий урбанизации, представителями которых являются С. Сассен [3], М. Кастельс [4], А.Н. Тетиор [5], позволяющие понять эволюцию города, связанную с расширением городской территории и вытеснением природной среды; теория «общества риска», которая позволяет учитывать и систематизировать риски развития современного города.

Концептуальными для исследования являются идеи теоретиков «зеленой экономики» К. Буркарта², Дж. Андреа, К. Бернс [6], концепции экосити Р. Реджистера [7], П. Даунтона [8] и др.

Данные подходы позволяют исследовать возможности «зеленой» экономики в решении экологических проблем современного города.

Обсуждение. В настоящее время в научном сообществе идет активное обсуждение проблем «зеленой» экономики, формируется понятийный аппарат в этой области исследований, выстраивается структура данной модели экономического развития общества.

Зарубежные авторы предлагают понимать под «зеленой» экономикой устойчивую систему развития экологии, экономики и общества. По мнению К. Буркарта, в системе «экология-экономика-общество» элементом, обеспечивающим ее стабильность, является экология, тогда как экономика представляет собой наименее устойчивый компонент данной системы ${ }^{3}$, поэтому дальнейшее существование этой системы возможно только при условии доминирования в ней экологического компонента.

Аналогичной позиции придерживаются и такие исследователи, как Дж. Андреа, К. Бернс, Дж. Туза, связывающие дальнейшее устойчивое развитие человечества исключительно с развитием «зеленой» экономики, которая только и «способна стабилизировать экономические системы и сбалансировать интересы человека, природы и эффективного использования ресурсов» [6, с. 84].

Проблематика «зеленой» экономики интересует и российских ученых. Исследователи утверждают, что «время неспешного перехода к “зеленой” экономике прошло - сегодня в ответ на последствия кризиса и в связи с потерей рабочих мест и необходимостью смягчения климатических изменений требуется быстрый планетарный переход к “зеленой” экономике. Цели ее весьма амбициозны, она способна обеспечить синергизм между тремя основными уровнями развития - экономическим ростом, социальным благополучием и охраной окружающей среды и здоровья людей» [9, с. 31].

Рассматривая структуру «зеленой» экономики, специалисты в качестве базового ее элемента называют «зеленую» промышленность, которая есть «процесс промышленного производства и совершенствования, осуществляющийся без уничтожения систем природы, не приводит к неблагоприятным

1 Харви Д. Городской опыт. [Электронный ресурс]. URL: http://psychogeo.spb.ru/page_255.html (дата обращения: 11.05.2019).

2 Burkart K. How Do You Define the «Green» Economy? MNN [Электронный pecypc] // Mother Nature Network. URL: http://www.mnn. com/greentech/research-innovations/blogs/how-do-you-define-the-green-economy (дата обращения: 14.06.2021).

3 Ibid. 
результатам, которые влияют на здоровье человека» ${ }^{4}$.

Таким образом, ученые связывают будущее экономики с развитием в ней следующих направлений [10]:

1) экологизация производства за счет рационального использования природных ресурсов;

2) создание «зеленых» отраслей промышленности за счет инкорпорирования в них экотехнологий и развития различных экологических услуг.

В настоящее время понятие «зеленая экономика» вошло в научный дискурс, который представлен различными подходами к пониманию ее сущности, структуры, возможностей реализации в пространстве современного города и пр. Подходы по данной проблеме можно классифицировать на несколько кластеров: экономический, технологический и аксиологический.

1. Экономический подход к «зеленой» экономике разрабатывается в работах как зарубежных, так и отечественных ученых. Анализируя возможности реализации новой модели экономики в развивающихся странах, китайские ученые выявили связь между практическим воплощением этой модели и методами «зеленого» управления [11]. По их мнению, «зеленая» экономика возможна только при условии «зеленого» управления. Российские исследователи связывают переход к «зеленой» экономике со сменой нынешней модели сугубо рыночной экономики, которая продемонстрировала свою несостоятельность как в плане природопользования, так и возможностей вывода стран из мирового экономического кризиса [9]. Представители экономического подхода к «зеленой» экономике видят дальнейшее развитие исключительно на основе «создания новых экологически чистых отраслей за счет спроса со стороны государства и формирования нового спроса и новой культуры потребления со стороны общества» $[12$, с. 132].

2. Технологический подход в качестве ключевого фактора диверсификации хозяйственной деятельности видит технологичес- кие инновации, обеспечивающие «создание экологически чистых промышленных и продовольственных товаров» [13, с. 114]. По мнению сторонников этого подхода, эффективное решение экологических проблем лежит сугубо в плоскости развития науки и технологий: «экологически опасные технологические процессы должны быть ресурсосберегающими и экологизированными в рамках системной экологизации производства» [14, с. 21]. Прежде всего, речь идет о создании низкоотходных технологических производств с максимально замкнутыми циклами, разработке и внедрении систем утилизации и обезвреживания отходов, глубокой очистке сточных вод и т.д.

3. Аксиологический подход связывает развитие «зеленой» экономики с формированием в социуме экологической культуры, которая и станет основой трансформации нынешней экономической модели, опирающейся на ценности либерализма и рыночного фундаментализма, на экогуманистическую модель отношений в системе «экология-экономика-общество». По мнению специалистов, данный подход «декларирует базовые ценности “зеленой” экономики: гармонизация отношений через взаимодействие человечества и биосферы, развитие человечества в границах законов развития биосферы, осознанные ограничения на потребление ресурсов биосферы и удовлетворение потребностей с учетом возможностей биосферы» [12, с. 136].

Надо отметить, что вышеперечисленные подходы к анализу «зеленой» экономики и ее возможностей в решении экологических проблем являются концептуальными только на интегративной основе, поскольку практическая реализация модели «зеленой» экономики предполагает комплексный подход, включающий экономические, технологические и аксиологические способы обеспечения экологической безопасности урбанизированных территорий.

Результаты. Исследователи отмечают, что экологизация экономики является основ-

4 Инициатива ЮНИДО в области «зеленой» промышленности по устойчивому промышленному развитию. Вена: ЮНИДО, 2011 [Электронный ресурс]. URL http://www.greenindustryplatform.org/wp-content/2014/06/ UNIDO-Green-IndustryInitiative-for-Sustainable-Industrial-Development_RU.pdf. 
ным фактором в появлении и развитии экогородов. В научной литературе для описания последних используются преимущественно понятия «экосити», «экополис».

Впервые термин «экосити» ввел в 1978 г. американский инженер и эколог Ричард Реджистер. По его мнению, экосити - «экологически чистый город, который способен самостоятельно обеспечивать себя продовольствием и энергией, при этом площадь, отчужденная под строительство, и, следовательно, жилая зона, должна быть по возможности минимальна» [7, с. 32]. В конце 80-х годов XX века в процессе обсуждения дальнейшего развития городских территорий в плане восстановления их экосистем начинает использоваться понятие «экополис», посредством которого описывается «урбанизированная система, население которой намеренно интегрировано в процессы биосферы для оптимизации функционирования биосферы на благо человека» $[8$, с. 26].

Аналогичную позицию относительно сущности экополиса занимает и отечественный ученый А.Н. Тетиор, который экосити рассматривает как «город, построенный на принципах экологичности, находящийся в экологическом равновесии с природой и не отторгаемый природными экосистемами, не загрязняющий природу и пронизанный зелеными коридорами, с нишами для жизни диких животных, с экологичными зданиями и экологизацией всей деятельности людей в городе, с высоким качеством жизни, системой экологического образования, воспитания и вовлечения всех жителей в процесс экологизации их жизни и деятельности» $[15$, с. 26].

Российские исследователи утверждают, что в основе развития экополиса лежат, прежде всего, экологичное производство и экологическая культура, которые интегрированно способны обеспечить устойчивое состояние городской экосистеме. Очевидно, что основной характеристикой экополиса является минимизация его негативного воздействия на флору и фауну городской англомерации.

Анализируя условия создания современных экогородов, ученые выделяют ряд направлений развития, реализация которых позволит городу стать экополисом:

1) «зеленое» строительство, ориентированное на энергоэффективность городов, которое обеспечивается за счет «использования комплекса современных технических разработок, направленных на получение и сохранение различных видов энергии их эффективное применение, а также внедрение в строительную практику» [16, с. 72];

2) практика использования возобновляемых источников энергии (ветрогенераторов, солнечных батарей, биогаза из сточных вод);

3) широкое внедрение различных видов экологического транспорта - электрический, биотопливный, велосипедный;

4) эффективная утилизация отходов, предполагающая как внедрение новых технологий сбора и переработки мусора, так и формирование экологической культуры у населения. Основной тенденцией городского развития, по мнению специалистов, должен стать «“безотходный образ жизни”, при котором все отходы полностью перерабатываются, а продукты этой переработки используются для обеспечения жизнедеятельности города» [16, с. 73];

5) развитие экологической инфраструктуры, которая представляет собой «комплекс взаимодействующих природных, природноантропогенных и искусственных объектов и систем, обеспечивающих условия сохранения среды жизни человека. Основная ее задача - обеспечение условий для сохранения естественной природной среды» [16, с. 73].

Выделение этих направлений позволяет рассматривать современный экополис как урбанизированную территорию с экологически и экономически эффективно организованной промышленностью и экологическим сознанием населения, поэтому реализация проекта экополиса возможна только на базе «зеленой» экономики, функционирующей на основе технологических инноваций и не разрушающих биосферу или минимизирующих негативное воздействие на нее.

В настоящее время стремление к реализации модели «зеленой» экономики наблюдается во многих городах мира, которые стремятся стать экосити или экополисами. Успешный опыт преобразования традиционных городов в экосити имеется как в ряде европейских стран и США, так и в ОАЭ, Китае, Японии, Новой Зеландии.

С 2006 года в Объединенных Арабских Эмиратах в районе Абу-Даби осуществляется 
проект строительства современного экополиса - Масдар-Сити. Планируется, что этот город будет функционировать исключительно на альтернативных источниках энергии с нулевым выбросом углерода. В качестве основных источников энергии в городе будут преимущественно использоваться природные факторы (ветер, солнце) и водородное топливо. В городе принципиально изменен подход к автомобильному транспорту, который ориентирован только на массовое использование электромобилей, поскольку нефть, газ и другие виды ископаемого топлива находятся под запретом. Кроме того, планировка города такова, что людям практически не требуется транспорт. Строительство этого экополиса должно завершиться в 2025 году, всего в городе смогут проживать до 50 тысяч человек 5 . Ключевыми факторами в реализации этого экопроекта является экономический и технологический фактор, на основе которых осуществляется городское строительство.

Технологический фактор доминирует и в создании нового китайского города Сино-Сингапур-Тяньцзинь-Экосити, ориентированного на развитие и внедрение в городское хозяйство экологических производств и источников энергии. Новый город, как утверждают специалисты, «характеризуется инновационными экологическими решениями городского пространства. Большинство инфраструктурных проектов будет значительно отличаться от применяемых сейчас. Планируется использовать легкое метро, общественный транспорт, велосипеды и автомобили без водителя, которые смогут самостоятельно прокладывать маршрут» $[17$, c. 66]. Целью этого проекта является строительство города, функционирование которого не будет оказывать разрушительное воздействие на природную среду и станет комфортным для человека.

Проект безотходного функционирования общества удачно осуществляется в Японии. Власти страны активно стимулируют предприятия на внедрение технологий по переработке использованного сырья и созданию экопродукции. Успешным примером является реализация программы ежемесячного сбора вторсырья по девяти категориям с выплатой денежных призов участникам в городе Фудзиесида. Реализуются программы господдержки производителей эко-продукции. Это касается и автомобильной отрасли, где «японские автокомпании Тойота и Хонда разработали несколько моделей автомобилей на топливных элементах, генерирующих электричество. Такие автомобили не загрязняют выхлопами атмосферу» [18, с. 127].

Интенсивная экологизация городов идет в Германии. Если еще в 60-70 годах XX века многие немецкие города считались зонами экологического бедствия, то начиная с конца 70-х годов благодаря активности движения «зеленых» ситуация стала меняться в лучшую сторону. Сегодня экологическая политика является приоритетной для ФРГ, в силу чего идет изменение городской инфраструктуры на основе «использования альтернативных источников энергии, передовых технологий в отрасли переработки мусора, экологизации сознания граждан» $[19$, с. 55$]$.

В частности, это коснулось Лейпцига, который был одним из самых загрязненных промышленных городов Германии, а на сегодняшний день считается экологически благополучной территорией. Именно развитие «зеленой» инфраструктуры города, включающей в себя «управление качеством воды, улучшение качества воздуха, строительство энергосберегающих сооружений, повышение биоразнообразия, производство экологически чистых продуктов питания, обеспечение экологически сбалансированного использования водных ресурсов и ресурсов почв» ${ }^{6}$ позволило решить многие экологические проблемы. Также в ФРГ эффективно функционирует система разделения отходов, которая носит всеобъемлющий характер.

Таким образом, развитие «зеленой» экономики кардинально трансформирует инфраструктуру города, основными элементами которой становятся: а) «зеленое» строительство, предполагающее использование энер-

5 Технологии будущего: экогорода [Электронный ресурc]. URL: https:// www.epochtimes.com.ua/ru/science/ ecology/tekhnologii-budushchego-ekogoroda-104275 (дата обращения 19.07.2021).

6 EPA. United States Environmental Protection Agency. What is Green Infrastructure? [Electronic resource]. URL: http: // water.epa.gov/infrastructure /greeninfrastructure/gi_what.cfm (дата обращения: 22.07.2021). 
госберегающих материалов; б) «зеленый» транспорт, работающий на возобновляемых ресурсах; в) рациональное управление отходами, применение сортировки и вторичной переработки отходов производства или мусора; г) комплексное озеленение городской территории (расширение природных зон, «зеленые» крыши и т.п.).

Невзирая на то, что в ряде развитых стран идет процесс реорганизации экономики на основе «зеленых» технологий и строительство экосити, состояние большинства современных городов характеризуется деградацией природной среды, что, конечно, ограничивает возможности дальнейшего развития городской территории, значительно ухудшает ее качество и соответственно здоровье населения.

Надо отметить, что для России проблема внедрения модели «зеленой» экономики в городское пространство является сверхактуальной, поскольку «экологическая обстановка в большинстве городов России оценивается как достаточно напряженная, а в ряде крупных городов, таких как Москва, Санкт-Петербург, Новосибирск, Самара, Екатеринбург и др., она оценивается как катастрофическая (с учетом техногенных факторов и плотности населения)» [20, с. 143]. Это определяет необходимость выбора нового вектора городского развития, который позволил бы разрешить противоречие между экономическим ростом и сохранением качества городской экосистемы.

В последнее время обсуждение создания комфортных городов в России ведется в рамках экономических и урбанистических форумов, где дается оценка состояния экологии городского пространства и рассматриваются подходы к решению экологических проблем. Одной из наиболее обсуждаемых концепций в рамках этих мероприятий стала теория «зеленого» города.

В научной литературе понятие «зеленый» город анализируется преимущественно через концепт «устойчивое развитие». Однако в научных исследованиях отсутствует его однозначное понимание. Это обусловлено тем обстоятельством, что понятие «устойчивость» чаще всего рассматривается как характеристика статики системы, ее нахождение в состоянии покоя, а не развития, поэтому применительно к социальных системам ученые стали говорить об устойчивом развитии. В этом аспекте концепция устойчивого развития, по мнению специалистов, должна учитывать интересы как сегодня живущих людей, так и будущих поколений. В частности, «устойчивое развитие рассматривается как развитие, при котором человечество способно удовлетворять свои потребности, не подвергая риску будущие поколения также удовлетворять свои потребности» [21, с. 136].

Ряд исследователей полагает, что реализация проекта устойчивого городского развития осуществима исключительно на основе «зеленой» экономики как альтернативе существующей рыночной экономической модели, создавшей благоприятные условия для появления «общества потребления». Ученые отмечают, что именно «недостатки либерально-рыночной идеологии, ставшие сегодня очевидными даже для неспециалистов, приводят к заключению, что рыночный путь развития принципиально несовместим с концепцией устойчивого развития. Принятая мировым сообществом концепция "зеленой экономики" призвана обеспечить согласование трех компонентов устойчивого развития - экономического, социального и экологического, поскольку устойчивое развитие отличается от экономического развития более жесткими ограничениями экологического характера» [22, с. 37].

Хочется отметить, что в России, начиная с 2012 года, были утверждены к реализации два проекта современного городского строительства — «Иннополис» и «Смарт-Сити-Казань», которые должны были воплотить идею соразвития технополиса и экополиса, то есть гармонизировать технологическое развитие общества с сохранением и воспроизводством окружающей среды. Создание городов нового типа обусловлено мировыми тенденциями к развитию территорий, призывающими внедрять экологическую инфраструктуру в практику развития городов.

Создание Иннополиса руководствовалось идеей «формирования наукограда по аналогии с Силиконовой долиной, где смогут жить, обучаться и работать студенты, молодые ученые и специалисты в сфере ITтехнологий» $[17$, с. 75]. Развитие инфраструктуры города предполагало наличие в нем комфортных условий для проживания и соот- 
ветствия современным экологическим требованиям - энергосбережения, использования возобновляемых ресурсов, вторичной переработки отходов, эксплуатации экологичного транспорта.

Следующий российский градостроительный проект «умного» города получил название «Смарт-Сити-Казань». Данный проект ориентирован на строительство современного технополиса, который станет благоустроенным местом для процветания экономической, образовательной и научной деятельности. При создании этого проекта также учитывались и экологические требования. В частности, в городе «на основе ряда экотехнологий планируется осуществляться: сбор и использование дождевой воды, внедрение методов возведения энергоэффективных и пассивных сооружений, сертифицированных системами LEED и BREEM, использование эко- и энергоэффективных материалов, в том числе фотопанелей» $[17$, с. 77]. Также проект включает переход общественного транспорта на возобновляемые источники энергии.

Надо отметить, что данные проекты по созданию техноэкополиса являются экспериментальными и, к сожалению, незавершенными в силу своей финансовой затратности и отсутствия инвестиций. Но, тем не менее, они наглядно иллюстрируют роль «зеленой» экономики в мировых трендах по развитию городских территорий.

Очевидно, что в России реализация модели «зеленой» экономики, которая посредством внедрения новых «зеленых» технологий должна привести к появлению «зеленых» городов, затрудняется в силу следующих причин.

Во-первых, в большинстве российских городов имеет место устаревшая инфраструктура и низкий уровень ее технологического обновления. Это определяет необходимость радикальной модернизации экономической сферы, в которой приоритет должен отдаваться развитию высокотехнологичных секторов экономики, способных создавать экологически чистые производства и обновлять социальную, транспортную и другие виды инфраструктуры города. Исследователи отмечают, что «для создания абсолютно новой модели экономики необходимо активное вмешательство со стороны государства посредством формирования механизма государственного регулирования, ориентированного на экологически чистые отрасли производства...» [23, с. 51].

Во-вторых, сырьевая модель российской экономики, которая ориентирована исключительно на получение прибыли от продажи невозобновляемых энергоресурсов. Доминирование сырьевого сектора экономики не только не обеспечивает устойчивое развитие общества, поскольку зависит от мировых цен на энергоносители, но и не способствует развитию инновационных производств, затрудняет технологическую модернизацию страны. Поэтому необходимы кардинальные изменения в ресурсной политике государства, поскольку, с точки зрения специалистов, «сама концепция "зеленого города" зависит от этой политики: одно дело - сохранение и развитие ресурсно-ориентированной экономики, и другое - ориентация на максимальное использование инноваций и альтернативных источников ресурсов» [24, с. 88].

В-третьих, неэффективная система управления отходами, сложившаяся в стране, привела многие российские города к ситуации «мусорного» коллапса. Социологические исследования подтверждают, что проблема утилизации отходов становится первостепенной для российских мегаполисов ${ }^{7}$.

Заключение. Вышеизложенное позволяет заключить: опыт развитых стран наглядно демонстрирует, что решение проблемы обеспечения экологической безопасности современного города возможно только на основе перехода к «зеленой» модели экономики, которая учитывает ограниченность природных ресурсов и необходимость сохранения экосистемы как базового элемента дальнейшего существования урбанизированной цивилизации. Кроме того, появление новых инновационных технологий, способных минимизировать ущерб биосферы от промышленной деятельности человека, открывает новые возможности для дальнейшего экономического развития.

7 Экологическая ситуация в России: мониторинг. ВЦИОМ. 05.04.2018. [Электронный ресурc]. URL: https:// wciom.ru/index.php?id=236\&uid=9026 (дата обращения 25.05.2021). 
Таким образом, достижение устойчивого развития современного города возможно только на основе отказа от рыночной системы хозяйствования и перехода к «зеленой» экономике, которая на основе технологических инноваций и массированного озеленения городских территорий способна улучшить качество жизни людей с учетом удовлетворения их экологических потребностей. Стоит отметить, что строительство экологически безопасных городов является достаточно сложным процессом, включающим не только экономическую и технологическую модернизацию городских территорий, но и формирование нового мировоззрения, в котором человек осознает свою ответственность перед экосистемой и понимает ее значимость в качестве жизненно важной среды своего обитания.

\section{Список источников} $252 \mathrm{c}$.

1. Вебер М. Город. М.: Strelka Press, 2017.

2. Пригожин И., Стенгерс И. Порядок из хаоса. М.: Прогресс, 1989. 432 с.

3. Сассен С. Когда города значат больше, чем государства // Новое время. 2003. №43. C. 44-62.

4. Castells M. The Power of Identity. Vol.2// The Information Age: Economy, Society and Culture. Oxford and Malden, Mass: Blackwell Publishers, 1997. 337 p.

5. Тетиор А.Н. Тенденции урбанизации Земли // Евразийский Союз Ученых (ЕСУ). 2015. №9(18). С. 11-15.

6. Andrea J.J., Burns C., Touza J. Renewable Energy as a Luxury? A Qualitative Comparative Analysis of the Role of the Economy in the EU's Renewable Energy Transitions During the «Double Crisis» // Ecological Economics, 2017. Vol. 142. P. 81-90.

7. Реджистер P. EcoCities: восстановление городов в равновесии с природой. М.: Изд-во Новое Сообщество, 2006. 334 с.

8. Даунтон П. Экополис: Архитектура и города против изменения климата. Аделаида: Springer, 2009. 607 с.

9. Захарова Т.В. «Зеленая» экономика как новый курс развития: глобальный и региональный аспекты // Вестник Томского государственного университета. Экономика. 2011. №4(16). C. 28-38.
10. Бексултанова А.И. Теоретические аспекты «зеленой» экономики // International scientific review. 2016. №5(15). C. 64-65.

11. Yang J., Zhang F., Jiang X., Sun W. Strategic Flexibility, Green Management and Firm Competitiveness in an Emerging Economy // Technological Forecasting and Social Change. 2015. Vol. 101. P. 347-356.

12. Вукович Н.А. «Зеленая» экономика: определение и современная эколого-экономическая модель // Вестник УрФУ. Серия экономика и управление. 2018. Т.17. №1. C. $128-145$.

13. Бочко В.С. Зеленая экономика: вторая вечная проблема человечества // Вестник УрФУ. Серия экономика и управление. 2014. №3. C. 128-145.

14. Половняк В.К., Фридланд С. В. Современные технические и технологические подходы к решению экологических проблем// Вестник Казанского технологического университета. 2009. №4. С. 17-25.

15. Тетиор А.Н. Экология города. М.: Академия, 2008. 336 с.

16. Юрзинова И. Л. Эко-города: современное состояние и перспективы // Экономика. Налоги. Право. 2014. №6. С. 71-73.

17. Романова А.Ю. Особенности современных реализуемых проектов «городов будущего» // Academia. Архитектура и строительство. 2015. №1. С. 65-78.

18. Набока Т.В. Экологический консьюмеризм как организованное движение // Инновационная наука. 2017. Т. 4. №4. C. $126-128$.

19. Белозеров В.К., Кирилина Е. Ю. Приоритеты экологической политики Федеративной Республики Германия в современных условиях // Русская политология - Russian Political Science. 2017. №3. C. 52-56.

20. Душкова Д. О., Кириллов С.Н. Зеленая инфраструктура города: опыт Германии // Вестник Волгоградского государственного университета. 2016. №2(35). С. 136-147.

21. Смолькин В.П. Устойчивое экологическое развитие: основные подходы и понятия // Вестник Северного (арктического) федерального университета. Серия: Гуманитарные и социальные науки. 2014. №5. С. 135-139.

22. Кузина Л.В. Зеленая экономика как альтернатива существующей рыночной эко- 
номике // Вестник МГУЛ - Лесной вестник. 2015. №4. C. 37-42.

23. Бахтинова В.О., Курдюков В.Н., Бадалян Л.Х. «Зеленая» экономика в России: основные направления реализации // Вестник современных исследований. 2019. №1.10(28). C. $50-56$.

24. Ермолаева П.О., Башева О.А., Яницкий О.Н., Ермолаева Ю.В., Кузнецова И.Б. Социально-экологическая «устойчивость через изменения» российских городов: поиск теоретико-методологических перспектив // Мониторинг общественного мнения: Экономические и социальные перемены. 2019. №2. С. $80-94$.

\section{References}

1. Veber M. Gorod [City]. Moscow: Strelka Press, 2017. 252 p. (In Russ.).

2. Prigozhin I., Stengers I. Porjadok iz haosa [Order from chaos]. Moscow: Progress, 1989. 432 p. (In Russ.).

3. Sassen S. Kogda goroda znachat bol'she, chem gosudarstva [When cities mean more than states]. Novoe vremja [New time]. 2003; (43): 44-62. (In Russ.).

4. Castells M. The Power of Identity. Vol.2// The Information Age: Economy, Society and Culture. Oxford and Malden, Mass: Blackwell Publishers, 1997. $337 \mathrm{p}$.

5. Tetior A.N. Tendencii urbanizacii Zemli [Trends in the urbanization of the Earth]. Evrazijskij Sojuz Uchenyh (ESU) [Eurasian Union of Scientists (EUU)]. 2015; 9(18): 11-15. (In Russ.).

6. Andrea J.J., Burns C., Touza J. Renewable Energy as a Luxury? A Qualitative Comparative Analysis of the Role of the Economy in the EU's Renewable Energy Transitions During the «Double Crisis» // Ecological Economics, 2017. Vol. 142. P. 81-90.

7. Redzhister R. EcoCities: vosstanovlenie gorodov $\mathrm{v}$ ravnovesii s prirodoj [EcoCities: restoring cities in balance with nature]. Moscow: Izd-vo Novoe Soobshhestvo, 2006. 334 p. (In Russ.).

8. Daunton P. Jekopolis: Arhitektura i goroda protiv izmenenija klimata [Ecopolis: Architecture and Cities against Climate Change]. Adelaida: Springer, 2009. 607 p. (In Russ.).

9. Zaharova T.V. «Zelenaja» jekonomika kak novyj kurs razvitija: global'nyj i regional'nyj aspekty [«Green» economy as a new course of development: global and regional aspects]. Vestnik Tomskogo gosudarstvennogo universiteta. Jekonomika [Bulletin of Tomsk State University. Economy]. 2011; 4(16): 28-38. (In Russ.).

10. Beksultanova A.I. Teoreticheskie aspekty «zelenoj» jekonomiki [Theoretical aspects of «green» economy] // International scientific review. 2016; 5(15): 64-65. (In Russ.).

11. Yang J., Zhang F., Jiang X., Sun W. Strategic Flexibility, Green Management and Firm Competitiveness in an Emerging Economy // Technological Forecasting and Social Change. 2015. Vol. 101. P. 347-356.

12. Vukovich N.A. «Zelenaja» jekonomika: opredelenie i sovremennaja jekologo-jekonomicheskaja model' [«Green» economy: definition and modern ecological-economic model]. Vestnik UrFU. Serija jekonomika i upravlenie [Vestnik UrFU. Economics and Management series]. 2018; 17(1): 128-145. (In Russ.).

13. Bochko V.S. Zelenaja jekonomika: vtoraja vechnaja problema chelovechestva [Green economy: the second eternal problem of mankind]. Vestnik UrFU. Serija jekonomi$k a$ i upravlenie [Bulletin of UrFU. Economics and Management series]. 2014; (3): 128-145. (In Russ.).

14. Polovnjak V.K., Fridland S.V. Sovremennye tehnicheskie i tehnologicheskie podhody $\mathrm{k}$ resheniju jekologicheskih problem [Modern technical and technological approaches to solving environmental problems]. Vestnik $\mathrm{Ka}$ zanskogo tehnologicheskogo universiteta [Bulletin of Kazan Technological University]. 2009; (4): 17-25. (In Russ.).

15. Tetior A. N. Jekologija goroda [Ecology of the city]. Moscow: Akademija, 2008. 336 p. (In Russ.).

16. Jurzinova I. L. Jeko-goroda: sovremennoe sostojanie i perspektivy [Eco-cities: current state and prospects]. Jekonomika. Nalogi. Pravo [Economy. Taxes. Right]. 2014; (6): 71-73. (In Russ.).

17. Romanova A. Ju. Osobennosti sovremennyh realizuemyh proektov «gorodov budushhego» [Features of modern ongoing projects of «cities of the future»]. Academia. Arhitektura $i$ stroitel'stvo [Academia. Architecture and construction]. 2015; (1): 65-78. (In Russ.).

18. Naboka T.V. Jekologicheskij kons'jumerizm kak organizovannoe dvizhenie [Ecolog- 
ical consumerism as an organized movement]. Innovacionnaja nauka [Innovative Science]. 2017; 4(4): 126-128. (In Russ.).

19. Belozerov V.K., Kirilina E. Ju. Prioritety jekologicheskoj politiki Federativnoj Respubliki Germanija v sovremennyh uslovijah [Priorities of environmental policy of the Federal Republic of Germany in modern conditions]. Russkaja politologija - Russian Political Science. 2017; (3): 52-56. (In Russ.).

20. Dushkova D. O., Kirillov S. N. Zelenaja infrastruktura goroda: opyt Germanii [Green infrastructure of the city: the experience of Germany]. Vestnik Volgogradskogo gosudarstvennogo universiteta [Bulletin of Volgograd State University]. 2016; 2(35): 136-147. (In Russ.).

21. Smol'kin V.P. Ustojchivoe jekologicheskoe razvitie: osnovnye podhody i ponjatija [Sustainable ecological development: basic approaches and concepts]. Vestnik Severnogo (arkticheskogo) federal'nogo universiteta. Serija: Gumanitarnye i social'nye nauki [Bulletin of the Northern (Arctic) Federal University. Series: Humanities and Social Sciences]. 2014; (5): 135-139. (In Russ.).
22. Kuzina L. V. Zelenaja jekonomika kak al'ternativa sushhestvujushhej rynochnoj jekonomike [Green economy as an alternative to the existing market economy]. Vestnik MGUL Lesnoj vestnik [Bulletin of MGUL - Forest Bulletin]. 2015; (4): 37-42. (In Russ.).

23. Bahtinova V.O., Kurdjukov V.N., Badaljan L.H. «Zelenaja» jekonomika v Rossii: osnovnye napravlenija realizacii [«Green» economy in Russia: the main directions of implementation]. Vestnik sovremennyh issledovanij [Bulletin of modern research]. 2019; 1.10(28): 50-56. (In Russ.).

24. Ermolaeva P.O., Basheva O.A., Janickij O.N., Ermolaeva Ju. V., Kuznecova I.B. Social'no-jekologicheskaja «ustojchivost' cherez izmenenija» rossijskih gorodov: poisk teoretiko-metodologicheskih perspektiv [Socioecological «sustainability through changes» of Russian cities: search for theoretical and methodological perspectives]. Monitoring obshhestvennogo mnenija: Jekonomicheskie i social'nye peremeny [Monitoring public opinion: Economic and social changes]. 2019; (2): 80-94. (In Russ.).

Статья поступила в редакиию 30.11.2021; одобрена после рецензирования 05.12.2021; принята к публикации 18.12.2021.

The article was submitted on 30.11.2021; approved after reviewing on 05.12.2021; accepted for publication on 18.12.2021.

\section{ИНФОРМАЦИЯ ОБ АВТОРАХ}

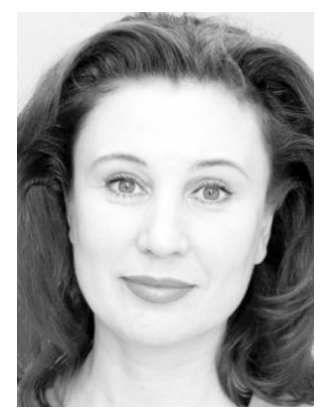

Майснер Татьяна Николаевна - кандидат философских наук, доцент, Южно-Российский государственный политехнический университет (НПИ) имени М.И. Платова.

Россия, г. Новочеркасск, ул. Просвещения, 132

Tatyana N. Meisner - Candidate of Philosophical Sciences, Associate Professor, Platov South Russian State Polytechnic University (NPI).

132 Prosveshcheniya st., Novocherkassk, Russia 